\title{
PREVALENCE OF TOBACCO USE AMONG SCHOOL TEACHERS AND EFFECT OF TRAINING ON TOBACCO USE IN WESTERN TURKEY
}

\author{
Gülengül Mermer ${ }^{1}$, Şafak Dağhan ${ }^{1}$, Ayşegül Bilge², Renginar Öztürk Dönmez¹, Süheyla Özsoy¹, Türkan Günay ${ }^{3}$ \\ ${ }^{1}$ Department of Public Health of Nursing, Nursing Faculty, Ege University, Izmir, Turkey \\ ${ }^{2}$ Department of Psychiatric and Mental Health Nursing, Nursing Faculty, Ege University, Izmir, Turkey \\ ${ }^{3}$ Department of Public Health, Medical Faculty of Dokuz Eylül University, Izmir, Turkey
}

\section{SUMMARY}

Background and Aim: Tobacco consumption is still a prevalent issue. Given that teachers are respected in society, they have a great responsibility for tobacco control. This study examines, using the Transtheoretical Model (TTM), the prevalence of tobacco use among teachers and their different stages of tobacco use. It also evaluates teachers' views on smoking and the effectiveness of training on tobacco use.

Methods: This study is quasi-experimental. Pre-test and post-test were used first with a cross-sectional group, then with a single group to determine the frequency of tobacco use. The research participation complied with the voluntary principles and the participation rate was $84.9 \%$. The research sample comprised 450 teachers working at schools $(N=17)$ under the Kemalpasa Directorate of Education. The data form contained 29 questions about socio-demographic characteristics and smoking habits. The Fagerstrom Test for Nicotine Dependence (FTND), Smoking Decisional Balance Scale (SDBS), and the Stage of Change were used. A pre-test was also administered, and training was given between January 13 and March 4, 2014. After the training sessions, two short messages (SMS) were sent on March 12 and March 19, 2014. A post-test was administered between April 1 and May 21, 2014. The relevant institutions and participants gave the requisite permission for the data used in this study. Percentage distribution, dependent t-tests and chi-square tests were used to evaluate the research data.

Results: The median age of the teachers was $37.49 \pm 7.84$. The teachers' mean score for the pre-test of FTND was $5.7 \pm 2.03$, and their mean score for the post-test was $3.25 \pm 2.07$. Post-test scores were remarkably lower than the pre-test scores. It was found that teachers' mean scores for SDBS were different before and after training. After training, anti-smoking attitudes increased (pros-cons scores: pre-test: $-3.64 \pm 4.68$, posttest: $-11.25 \pm 5.48$ ). The training helped the entire group to make progress in the process change.

Conclusion: After training on "the health effects of smoking", teachers' anti-smoking attitudes rose on the smoking decision balance scale, their nicotine dependency was reduced, and they were able to move forward in a positive direction.

Key words: nursing interventions, teacher, smoking, tobacco, transtheoretical model, Turkey

Address for correspondence: G. Mermer, Nursing Faculty, Ege University, 35100 Bornova, Izmir, Turkey. E-mail: gulengul.s.mermer@ege.edu.tr http://dx.doi.org/10.21101/cejph.a4217

\section{INTRODUCTION}

Tobacco use is one of the biggest public health issues. Roughly, there are 1.3 billion smokers worldwide, including a third of the world population aged over 15. It is indicated if the current smoking behaviours remain unchanged, this rate will reach two billion by the year 2030 . Nearly $80 \%$ of the more than one billion smokers worldwide live in low and middle income countries where the burden of tobacco related illness and death is substantial (1). Turkey ranks 10th in the list of countries with the highest rate of tobacco use (2). Tobacco endemic is a leading cause of death, illness, cancer, and impoverishment, resulting in nearly six million fatalities annually. Over $90 \%$ of these deaths are caused directly by tobacco use whilst about $10 \%$ are the results of non-smokers being exposed to second-hand smoke. If the current smoking behaviours remain unchanged, there will be worldwide increase in deaths up to more than eight million per year by 2030 (1). Smok- ers have a greater risk of cancer than nonsmokers (3). Smoking causes many serious diseases including cancer and strokes, and it shortens the life expectancy (4).

Most smokers began smoking before the age of 18. Thus, smoking prevention should be aimed at young people $(5,6)$. Children and adolescents learn smoking from their role models (7). Given that teachers are respected people, they have a great responsibility for tobacco control (8). The relevant literature suggests that teachers are also role models for students and key figures in tobacco prevention programmes $(8,9)$. Since teachers have regular interactions with students, they have a great opportunity to prevent them from smoking.

Particularly in developing countries, nurses have worked in smoking cessation and prevention programmes during the past ten years. Nursing interventions were performed in a planned manner, and smokers were informed and consulted. These programmes had successful results. The purpose of nursing intervention is to 
change smoking behaviour (10). The intervention plan is based on valid and reliable theoretical models. The Transtheoretical Model (TTM) concerns the stages of behaviour change. Stages are defined as "qualitatively distinct states in a behaviour change process." The Transtheoretical Model increases people's efforts to change and their levels of awareness $(11,12)$.

The literature suggests that teachers do not quit smoking because they do not know any method for quitting smoking (13). There are very few studies on tobacco smoking behaviours among teachers, and they were only cross-sectional. The effects of smoking prevention training on the levels of quitting smoking have not been examined in Turkey. Also, there are very few studies on tobacco smoking among teachers in Turkey (14-17). The aim of this study was to find out the prevalence of tobacco smoking among teachers in Turkey, determine the perception related to pros and cons of smoking among teachers, and evaluate effectiveness of smoking prevention training by nurses.

\section{MATERIALS AND METHOD}

\section{Design}

This quasi-experimental study determines the frequency of tobacco use. Pre-test and post-test were used first with a crosssectional group, and then with a single group.

\section{Study Population}

The research sample comprised teachers $(\mathrm{N}=530)$ working at primary and high schools $(\mathrm{N}=17)$ between May 16, 2013 and August 7, 2014 in Izmir. The research included teachers who were physically present in the schools (who were not on career leave or sick leave, or based in another region) and agreed to participate in the research $(\mathrm{N}=530)$.

Between January 13 and March 4, 2014, 466 teachers were interviewed to determine the frequency of tobacco use among teachers. Due to a lack of data, 16 surveyed participants were eliminated. The remaining 450 were analyzed (participation rate: $84.9 \%$ ). A pre-test was also conducted and a training session was held. It was found that 179 teachers were smokers.

Between April 1 and May 21, 2014 a post-test was conducted. During the post-test, five teachers had to leave the region due to health problems, and four teachers were based in a different region. Thus, the study included only 170 teachers (access rate: $95.0 \%)$.

\section{Instruments}

The socio-demographic data form, smoking habits data form, Fagerstrom Test for Nicotine Dependence (FTND), Smoking Decisional Balance Scale (SDBS) and the Stage of Change were used. The data form contained 29 questions about teachers' sociodemographic characteristics and smoking habits.

\section{Stages of Change}

The five stages of change in smoking behaviour were examined by the staging algorithm developed by Prochaska and
DiClemente (11). Karanci developed a Turkish version of the sample (19). Change process questions help indicate behaviour change not only related to smoking, but also to breast cancer, nourishment, exercise, and the use of condoms. The change process that a person goes through includes five stages (10): pre-contemplation, contemplation, preparation, action, and maintenance. Pre-contemplation is a stage in which people do not think of quitting smoking. Contemplation is a stage in which people think of quitting smoking in the next six months. Preparation is a stage in which people thought of quitting smoking in the last month or tried to quit smoking at least once. Action is the stage in which people have not smoked for the last six month. Maintenance is a stage in which people have not smoked for more than six months (11).

\section{Smoking Decisional Balance Scale}

The Smoking Decisional Balance Scale (SDBS) was developed by Velicer et al. The SDBS focus on the cognitive and motivational aspects of human decision making. Decisional balance refers to a smoker's relative weighing of the advantages and disadvantages (or pros and cons) of continued smoking. As people progress from "not intending to change" to "maintaining change", perceptions of the pros of smoking decrease and perceptions of the cons of smoking increase (20). Velicer et al. divided these aspects into two categories: the 'pros of smoking' and the 'cons of smoking.' Each category is determined according to a 12-item scale. The items scores were calculated by a five-point Likert scale that ranked between 1 (not important) and 5 (extremely important). The overall balance score was obtained by subtracting the total cons score from the total pros score, the positive scores indicated a balance in favour of the pros of smoking, while negative scores indicated that the cons of smoking outweighed pros. Also, it measures smoker's opinion on quitting. The Turkish version of SDBS was developed by Yalcinkaya and Karanci (21). In the present study, the internal consistencies for the pros and cons of smoking scales were 0.75 and 0.73 , respectively.

\section{Fagerstrom Test for Nicotine Dependence}

The Fagerstrom Test for Nicotine Dependence (FTND) was developed in 1978 by Fagerstrom to examine nicotine dependency using self-assessment methods (22). Uysal et al. developed the Turkish version of the scale (23). The FTND is composed of 6 questions. If the total test score is above 4 , it indicates a probability of dependence. The five degrees of nicotine dependency according to the test scores include very low dependency (0-2), low dependency (3-4), medium dependency (5), high dependency $(6,7)$, and very high dependency $(8-10)(24)$.

\section{Intervention}

To collect data, face-to-face interviews were conducted with the teachers in the classroom at the time assigned by school administrators. The teachers were informed about the purpose of study. Then data was collected with data collection tools, and a pre-test was administered.

The smoking teachers were trained on the "health effects of smoking" between January 13 and March 4, 2014. The training 
had 15 sessions. Each research participant attended training sessions once. Each training session was 65 minutes long, 20 minutes of data collection and 45 minutes lecture about the health effects of smoking. The training programme covers the smoking rates in Turkey and in the world, effects of smoking on health, diseases and physical harms caused by smoking, reasons for people start smoking and keep on smoking, meaning of tobacco use for teachers, smoking prevention and protection, tobacco control precautions, quitting smoking and behaviour change, quit smoking centres and their contact addresses. The number of teachers at each session varied between 10 and 14 (12 persons in five sessions, 11 persons in seven sessions and 14 persons in three sessions). SMS messages were sent to the teachers and administrators to remind them about the training sessions.

After the training, the Turkish Thoracic Society's motto, "Life starts with a breath," were sent as SMS (on March 12 and on March 19, 2014) to the teachers to enhance their motivation. About four weeks after training, the Fagerstrom Test for Nicotine Dependence, Smoking Decisional Balance Scale and the Stage of Change scales were administered.

\section{Measures}

It was expected that after training there would be reduction in teachers' levels of nicotine dependency, development in their awareness about the harms of smoking and progress in their change process.

\section{Data Analysis}

The Statistical Package for the Social Sciences (SPSS) was used. Number and percentage distributions were used to present the descriptive data. T-tests and chi-square tests were used to compare teachers' mean scores for each scale before and after training. The significance level was $p<0.05$. Effect sizes were determined to evaluate the effectiveness of the training. Effect size found was $\mathrm{p}>0.08(25)$.

\section{Ethical Approval}

The Ethics Committee of the Ege University Nursing Faculty approved the study and the Kemalpasa Directory of Education gave the requisite permission for this research. Participants also gave verbal and written consent.

\section{RESULTS}

Teachers' $(n=450)$ median age was $37.49 \pm 7.84$ years (from 22 to 61$)$. Most of the teachers $(60.9 \%)$ were below the age of 39 , married $(82.0 \%)$, and female $(59.6 \%) .87 .3 \%$ of the teachers had undergraduate education, and $63.1 \%$ of them had equal level of income and expenses.

It was found that $45.8 \%$ of the teachers have never smoked, and $27.8 \%(n=170)$ smoked regularly. The median age when they started smoking was $17.91 \pm 3.61$ (from 7 to 32 ), and the average years of continuous smoking were $17.68 \pm 7.20$ (from 3 to 36 ). Of the teachers, $42.7 \%$ said they were exposed to secondhand smoke, $10.2 \%$ said they smoked at home, $0.3 \%$ said they had received penalty notices for smoking in forbidden places, and 14.9\% said they wanted to obtain professional support to quit smoking.

Teacher's nicotine dependency is described in Table 1. The Fagerstrom Test was administered to assess the teachers' dependence on nicotine. Before training $39.4 \%$ of the teachers were highly addicted smokers, while after training $39.4 \%$ had very low levels of nicotine addiction. This difference is statistically significant $\left(\chi^{2}=127.525, \mathrm{p}<0.001\right)$. Before training the mean nicotine-dependence test score was $5.71 \pm 2.03$, while after training the mean NBT score was $3.25 \pm 2.07$. The difference in the mean scores before and after training is statistically significant $(t$ $=-11.036, \mathrm{p}<0.001)$. The effect size was found to be 1.2 with regard to the difference in the mean scores before and after training. Socio-demographic variables and mean NBT scores of teachers were compared. It was found that after training the mean NBT score was $1.00 \pm 1.48$ for women and $3.21 \pm 1.59$ for men. The difference in the mean scores according the gender was statistically significant $(\mathrm{t}=-2.818, \mathrm{p}=0.005)$. However, the marital status, education attained, administrative status and demand for professional support were without statistical significance $(p>0.05)$.

Stages of change in smoking behaviour of teachers are shown in Table 2. There were five teachers who said that they quit smoking after training. The teachers' change process was evaluated. Before training, $26.3 \%$ were in the pre-contemplation stage, $16.8 \%$ were in the contemplation stage, and $56.9 \%$ were in the preparation stage. After training, $24.2 \%$ were in the pre-contemplation stage, $24.1 \%$ were in the contemplation stage, $60.1 \%$ were in the preparation stage, and $1.1 \%$ were in the action stage. Chi-square test was used to examine the differences in the change process. The difference is statistically significant $\left(\chi_{\text {pre-contemplation }}^{2}=56.376\right.$, $\mathrm{p}<0.001 ; \chi_{\text {contemplation }}^{2}=59.379, \mathrm{p}<0.001 ; \chi_{\text {preparation }}^{2}=63.391$, $\mathrm{p}<0.001 ; \chi_{\text {action }}^{2}=1.506, \mathrm{p}<0.001$ ) (Table 2).

Before training, the pros of smoking score was $36.54 \pm 2.86$, while after training it was $34.57 \pm 4.00$. The difference is statistically significant $(\mathrm{t}=7.666, \mathrm{p}<0.001)$. Before training, the cons of smoking score was $40.18 \pm 3.86$, while after training cons score was $45.80 \pm 3.73$. The difference is statistically significant $(\mathrm{t}=25.393, \mathrm{p}<0.001)$. The pros-cons score was $3.64 \pm 4.68$ before training and $45.80 \pm 3.73$ after training. The difference is statistically significant $(\mathrm{t}=-25.393, \mathrm{p}<0.001)$. The pros-cons score was $-3.64 \pm 4.68$ before training and $-11.25 \pm 5.48$ after training. The difference is statistically significant $(t=22.195, \mathrm{p}<0.001)$ (Table $3)$. The effect size for the pros-cons score is 1.33 .

\section{DISCUSSION}

Given that teachers are students' role models, it is particularly important that teachers do not smoke $(5-9,26)$. The literature suggests that the TTM provides an effective way to quit smoking $(11,12)$. The Stage of Change and Smoking Decisional Balance Scale were used in this study. Research sample included teachers who worked in the schools under the Kemalpasa Directorate of Education. It is the first study conducted in a rural area of Izmir. It should be emphasize that the research results can be generalized only to the rural areas of Izmir.

Smoking control programmes of countries were decisive factors in quitting smoking. In the Turkey Tobacco Control Policy the programme has been applied very effectively in the last decade. 
Table 1. Distribution of teachers' nicotine addiction test items before and after training $(n=170)$

\begin{tabular}{|c|c|c|c|c|}
\hline \multirow{2}{*}{ Nicotine dependence } & \multicolumn{2}{|c|}{ Before training } & \multicolumn{2}{|c|}{ After training } \\
\hline & Number & $\%$ & Number & $\%$ \\
\hline \multicolumn{5}{|c|}{ How many cigarettes a day do you smoke? } \\
\hline 10 or less & 71 & 41.8 & 2 & 1.2 \\
\hline $11-20$ & 39 & 22.9 & 73 & 42.9 \\
\hline $21-30$ & 13 & 7.6 & 30 & 17.6 \\
\hline 31 or more & 47 & 27.6 & 65 & 38.2 \\
\hline \multicolumn{5}{|c|}{ How soon after waking do you smoke your first cigarette? } \\
\hline Within 5 minutes & 44 & 25.9 & 12 & 7.1 \\
\hline $6-30$ minutes & 77 & 45.3 & 70 & 42.1 \\
\hline $31-60$ minutes & 27 & 15.9 & 47 & 27.6 \\
\hline After 61 minutes & 22 & 12.9 & 41 & 24.1 \\
\hline \multicolumn{5}{|c|}{ Do you find it difficult refrain from smoking in places where it is forbidden? E.g. bus, library etc. } \\
\hline Yes & 73 & 42.9 & 47 & 27.6 \\
\hline No & 97 & 57.1 & 123 & 72.4 \\
\hline \multicolumn{5}{|c|}{ Which cigarette would you hate to give up? } \\
\hline The first in the morning & 82 & 48.2 & 55 & 32.4 \\
\hline Any other & 88 & 51.8 & 115 & 67.6 \\
\hline \multicolumn{5}{|c|}{ Do you smoke more frequently in the morning? } \\
\hline Yes & 82 & 48.2 & 54 & 31.8 \\
\hline No & 88 & 51.8 & 116 & 68.2 \\
\hline \multicolumn{5}{|c|}{ Do you smoke even if you are sick in the bed most of the day? } \\
\hline Yes & 74 & 43.5 & 50 & 39.4 \\
\hline No & 96 & 56.5 & 120 & 70.6 \\
\hline Total & 170 & 100.0 & 170 & 100.0 \\
\hline \multicolumn{5}{|l|}{ Dependence level } \\
\hline Very Low & 16 & 9.4 & 67 & 39.4 \\
\hline Low & 32 & 18.8 & 54 & 31.8 \\
\hline Moderate & 25 & 14.7 & 27 & 15.9 \\
\hline High & 67 & 39.4 & 18 & 10.6 \\
\hline \multirow[t]{2}{*}{ Very High } & 30 & 17.6 & 4 & 2.4 \\
\hline & \multicolumn{4}{|c|}{$X^{2}=127.525, p<0.001$} \\
\hline
\end{tabular}

It is strictly forbidden for students as well as teachers to smoke in school (29). Despite these regulations, the literature suggests that teachers' rates of smoking are higher in Turkey than in other countries $(5,9,14,15,26-28)$. The percentage of Turkish teachers who smoke varies between $45.7 \%$ and $58.1 \%(14,17$, 27). According to this study, one of three teachers was a smoker. Although teachers' rates of smoking are higher in Turkey, it was found that smoking behaviour did start at earlier ages, and that the teachers had smoked for $17.68 \pm 7.20$ years on average. The teachers' attitudes towards smoking affect adolescents' decision to start smoking $(6,17)$. That is why teachers have a great responsibility to prevent youth from smoking.

The Turkey Adult Smoking Research (2010) and regional studies showed that most of the adults smoked more than 10 cigarettes a day $(14,15,29)$. A third of the teachers were highly addicted before training compared to only one-tenth of them highly addicted after training (Table 1). After training, their nicotine dependence score was reduced from $5.71 \pm 2.03$ to $3.25 \pm 2.07$. The nicotine dependency score before training was higher than the scores reported by other studies $(24,27)$. The effect of the training may help to explain the reduction in the nicotine addiction levels.

Male teachers had higher levels of nicotine dependence than female teachers $(p<0.05)$. The literature also provides evidence that, compared to women, men smoked more cigarettes daily, had smoked longer and had higher levels of nicotine addiction $(8,15,18,27,30)$. So, gender is a determinant factor in smoking behaviours. The reduction in addiction scores of male participants in particular showed the effectiveness of training.

The training enabled the participants to move to the stages of pre-contemplation and contemplation, and thus to make a remarkably positive change. At the end of training, a quarter of the teachers were in the stage of contemplation. The literature suggests that this rate is usually one-tenth before training (30). So, after the training, the number of people in the contemplation stage doubled. 
Table 2. Distribution of teachers' answers to the questions about change process before and after training $(n=170)$

\begin{tabular}{|c|c|c|c|c|}
\hline \multirow{2}{*}{$\begin{array}{l}\text { Questions about change } \\
\text { process }\end{array}$} & \multicolumn{2}{|c|}{ Before training } & \multicolumn{2}{|c|}{ After training } \\
\hline & Number & $\%$ & Number & $\%$ \\
\hline \multicolumn{5}{|c|}{ Have you ever thought about quitting smoking? } \\
\hline Yes & 65 & 38.2 & 106 & 62.4 \\
\hline No & 105 & 61.8 & 64 & 37.6 \\
\hline \multicolumn{5}{|c|}{ Do you think seriously about quitting smoking in the next six months? } \\
\hline Yes & 62 & 36.5 & 102 & 63.5 \\
\hline No & 108 & 63.5 & 68 & 36.5 \\
\hline \multicolumn{5}{|c|}{ Do you think seriously about quitting smoking next month? } \\
\hline Yes & 45 & 26.5 & 83 & 48.8 \\
\hline No & 125 & 73.5 & 87 & 51.2 \\
\hline \multicolumn{5}{|c|}{ Did you try to quit smoking in the last six months? } \\
\hline Yes & 57 & 33.5 & 93 & 54.7 \\
\hline No & 113 & 66.5 & 77 & 45.3 \\
\hline \multicolumn{5}{|c|}{ Do you currently smoke cigarettes? } \\
\hline Yes & 170 & 100.0 & 165 & 97.1 \\
\hline No & 0 & 0.0 & 5 & 2.9 \\
\hline \multicolumn{5}{|l|}{ Stages of change } \\
\hline \multirow{2}{*}{ Pre-contemplation } & 45 & 26.3 & 41 & 24.2 \\
\hline & \multicolumn{4}{|c|}{$x^{2}=56.376, p<0.001$} \\
\hline \multirow{2}{*}{ Contemplation } & 28 & 16.8 & 41 & 24.1 \\
\hline & \multicolumn{4}{|c|}{$X^{2}=59.379, p<0.001$} \\
\hline \multirow{2}{*}{ Preparation } & 97 & 56.9 & 102 & 60.1 \\
\hline & \multicolumn{4}{|c|}{$x^{2}=63.391, p<0.001$} \\
\hline \multirow{2}{*}{ Action } & 0 & 0.0 & 5 & 1.1 \\
\hline & \multicolumn{4}{|c|}{$x^{2}=1.506, p<0.001$} \\
\hline
\end{tabular}

No remarkable difference in the numbers of teachers in the stage of preparation before and after training was found. However, the literature suggests that there should have been higher numbers of teachers at the preparation stage $(16,17,21)$.

Of the teachers, $54.7 \%(n=93)$ tried to quit smoking in the last six months, but only five of them have never smoked in the last six months. Of those who quit smoking, 70\% began to smoke again in the first three months (24). The research data also supports this finding. Thus, smokers who are attempting to quit need more support and more frequent consultations with healthcare workers.

At the end of this study teachers' perception of 'cons' increased as expected. The literature provides evidence that there was a decrease in the perceived 'pros of smoking' and an increase in the perceived 'cons of smoking' of the participants after training $(20,21)$. Furthermore, the teachers' awareness about the harms of smoking increased. This was an intended result of the training sessions. As negative attitudes towards smoking increase, behavioural change happens more easily $(2,21)$.

\section{CONCLUSION}

Based on the Transtheoretical Model, nurses trained teachers about the health effects of smoking. They helped teachers become aware of the harms of smoking, reduce their levels of nicotine addiction and initiate positive behavioural change. Thus, the training was useful and effective.

It is recommended that students and teachers, as students' role models, organize training sessions about the health effects of smoking in a reliable and valid theoretical framework. Training sessions can be planned according to the participant's stage of change, and the results of this training can be used in the teacher training programmes to further theoretical arguments and develop initiation strategies. It is possible to organize regular training sessions about the health effects of smoking given by nurses in health institutions or at schools. The observation and evaluation process should be of significant duration to obtain effective results.

\section{Acknowledgements}

The authors would like to thank the Ege University Research Fund for funding this research and the personnel of Kemalpasa Directory of Education and participant schools in Kemalpasa, Izmir, for their support in carrying out the research, and are grateful to the teachers for their participation in this study.

\section{Conflict of Interests}

None declared 
Table 3. Mean scores of decisional balance scale for smoking of teachers before and after training $(n=170)$

\begin{tabular}{|c|c|c|}
\hline \multirow{2}{*}{ Smoking decisional balance scale items } & Before training & After training \\
\hline & mean $\pm S D$ & mean $\pm S D$ \\
\hline Smoking cigarettes is pleasurable & $3.37 \pm 0.56$ & $3.24 \pm 0.75$ \\
\hline After not smoking, for a while a cigarette makes me feel great & $3.35 \pm 0.65$ & $3.15 \pm 0.61$ \\
\hline Sometimes smoking or getting cigarettes is an inconvenience & $2.67 \pm 0.60$ & $3.20 \pm 0.75$ \\
\hline I feel I am a slave to my smoking habit & $2.56 \pm 0.52$ & $3.10 \pm 0.55$ \\
\hline I am relaxed and therefore more pleasant when I am smoking & $3.51 \pm 0.52$ & $3.42 \pm 2.34$ \\
\hline Other smokers will be jealous if I quit & $3.40 \pm 0.65$ & $3.10 \pm 0.59$ \\
\hline I like the image of a cigarette smoker & $3.29 \pm 0.68$ & $2.88 \pm 0.56$ \\
\hline My smoking can affect the health of others & $3.02 \pm 0.72$ & $3.40 \pm 0.73$ \\
\hline I would be more energetic right now if I did not smoke & $2.96 \pm 0.72$ & $3.46 \pm 0.69$ \\
\hline When I smoke I feel more accepted by family or friends who smoke & $3.48 \pm 0.58$ & $3.38 \pm 0.83$ \\
\hline If I try to stop smoking I will probably be irritable and difficult to be around & $2.79 \pm 0.96$ & $3.17 \pm 0.81$ \\
\hline Others close to me would suffer if I became ill from smoking & $3.90 \pm 0.91$ & $4.32 \pm 0.82$ \\
\hline My family and friends like me better when I am happily smoking than when I am miserably trying to quit & $3.04 \pm 0.82$ & $2.41 \pm 1.04$ \\
\hline Because I continue to smoke, some people I know think I lack character to quit & $3.15 \pm 0.75$ & $3.42 \pm 0.72$ \\
\hline Smoking cigarettes is hazardous to my health & $4.07 \pm 0.70$ & $4.62 \pm 0.69$ \\
\hline I am embarrassed that I have to smoke & $2.78 \pm 0.78$ & $3.10 \pm 0.86$ \\
\hline My cigarette smoke bothers other people & $3.53 \pm 0.74$ & $3.78 \pm 0.79$ \\
\hline People think I am foolish for ignoring warnings about cigarette smoking & $2.33 \pm 0.87$ & $2.90 \pm 0.82$ \\
\hline I like myself better when I smoke & $3.08 \pm 0.81$ & $2.97 \pm 1.02$ \\
\hline Smoking helps me concentrate and do better work & $3.23 \pm 0.67$ & $3.27 \pm 0.94$ \\
\hline Smoking cigarettes relieves tension & $3.35 \pm 0.64$ & $3.35 \pm 0.64$ \\
\hline People close to me disapprove of my smoking & $3.79 \pm 0.82$ & $3.29 \pm 0.72$ \\
\hline I am foolish to ignore the warning about cigarettes & $2.61 \pm 0.80$ & $3.07 \pm 0.75$ \\
\hline By continuing to smoke I feel I am making my own decisions & $3.41 \pm 0.55$ & $3.47 \pm 0.69$ \\
\hline \multirow{2}{*}{ Pros of smoking } & $36.54 \pm 2.86$ & $34.57 \pm 4.00$ \\
\hline & \multicolumn{2}{|c|}{$t=7.666, p<0.001$} \\
\hline \multirow{2}{*}{ Cons of smoking } & $40.18 \pm 3.86$ & $45.80 \pm 3.73$ \\
\hline & \multicolumn{2}{|c|}{$t=-25.393, p<0.001$} \\
\hline \multirow{2}{*}{ Pros-cons score } & $-3.64 \pm 4.68$ & $-11.25 \pm 5.48$ \\
\hline & \multicolumn{2}{|c|}{$t=22.195, p<0.001$} \\
\hline
\end{tabular}

\section{Authors' Contributions}

GM: study design, data collection, data analysis, manuscript preparation; SD: data analysis, data collection, drafting of manuscript; AB: data analysis, data collection, drafting of manuscript; RÖD: data analysis, data collection, drafting of manuscript; SO: critically reviewed the manuscript for final publication; TG: critically reviewed the manuscript for final publication.

\section{REFERENCES}

1. WHO report on the global tobacco epidemic, 2008: the MPOWER package [Internet]. Geneva: WHO; 2008 [cited 2014 Oct 15]. Available from: http://www.who.int/tobacco/mpower/mpower_report_full_2008.pdf.

2. Bilir N, Çakır B, Daglı E, Ergüder T, Önder Z. Tobacco Control in Turkey [Internet]. Copenhagen: WHO Regional Office for Europe; 2009 [cited 2014 Oct 15]. Available from: http://www.euro.who.int/_data/assets/ pdf_file/0004/98446/E93038.pdf.
3. Heydari G, Yousefifard M, Hosseini M, Ramezankhani A, Masjedi MR. Cigarette smoking, knowledge, attitude and prediction of smoking between male students, teachers and clergymen in Tehran, Iran, 2009. Int J Prev Med. 2013 May;4(5):557-64.

4. Christie J. Interventions for recruiting smokers into cessation programmes: a review summary. Public Health Nurs. 2014 Jan-Feb;31(1):55-7.

5. Shah PB, Pednekar MS, Gupta PC, Sinha DN. The relationship between tobacco advertisements and smoking status of youth in India. Asian Pac J Cancer Prev. 2008 Oct-Dec;9(4):637-42.

6. Huang HW, Lu CC, Yang YH, Huang CL. Smoking behaviours of adolescents, influenced by smoking of teachers, family and friends. Int Nurs Rev. 2014 Jun;61(2):220-7.

7. Virtanen M, Pietikäinen M, Kivimäki M, Luopa P, Jokela J, Elovainio M, et al. Contribution of parental and school personnel smoking to health risk behaviours among Finnish adolescents. BMC Public Health. 2009 Oct 9;9:382.

8. Al-Naggar RA, Jawad AA, Bobryshev YV. Prevalence of cigarette smoking and associated factors among secondary school teachers in malaysia. Asian Pac J Cancer Prev. 2012; 13(11):5539-43.

9. Savadi P, Wantamutte AS, Narasannavar A. Pattern of tobacco use among primary school teachers in Belgaum city, India - A Cross Sectional Study. Glob J Med Publ Health. 2013;2(4):1-6. 
10. Chouinard MC, Robichaud-Ekstrand S. The effectiveness of a nursing inpatient smoking cessation program in individuals with cardiovascular disease. NursRes. 2005 Jul-Aug;54(4):243-54.

11. Prochaska JO, DiClemente CC. Stages and processes of self-change of smoking: toward an integrating model of change. J Consult Clın Psych. 1983;51(3):390-95.

12. Guo B, Aveyard P, Fielding A, Sutton S. Do the Transtheoretical Model processes of change, decisional balance and temptation predict stage movement? Evidence from smoking cessation in adolescents. Addiction. 2009;104(5):828-38.

13. Al Nasir FA, Skerman JH. Schoolteachers' knowledge of common health problems in Bahrain. East Mediterr Health J. 2004 JulSep;10(4-5):537-46.

14. Ünsal M, Hamzaçebi H, Dabak S, Terzi O, Kirişoğlu T. Smoking status and levels of knowledge regarding cigarettes among primary school teachers. South Med J. 2008;101(12):1227-31.

15. Çoban SA, Sungur G. Teachers' behaviours and opinions on the cigarette smoking. Turkish Thoracic Journal. 2013;14(3):98-102. (In Turkish.)

16. Yıldız F, Barış SA, Başyiğit İ, Boyacı H. Evaluation of Smoking habits of teachers who work in city centre of Kocaeli. Türkiye Klinikleri Arch Lung. 2011;12(1):9-12. (In Turkish.)

17. Kutlu R, Civi S. The frequency and affecting factors of smoking among the high school teachers in Konya. TAF Prev Med Bull. 2007;6(4):273-28.

18. İnandı T, Caman ÖG, Aydın N, Önal AE, Kaymaz A, Turhan E, et al. Global Health Professions Student Survey - Turkey: second-hand smoke exposure and opinions of medical students on anti-tobacco law. Cent Eur J Public Health. 2013;21(3):134-9.

19. Karanci AN. Self-efficacy-based smoking situation factors: the effects of contemplation quitting versus relapsing in a Turkish sample. Int J Addict.1992;27(7):879-86.

20. Velicer WF, DiClemente CC, Prochaska JO, Brandenburg N. Decisional balance measure for assessing and predicting smoking status. J Pers Soc Psychol.1985;48(5):1279-89.
21. Yalçinkaya-Alkar O, Karanci AN. What are the differences in decisional balance and self-efficacy between Turkish smokers in different stages of change? Addict Behav. 2007; 32(4):836-49.

22. Fagerström KO. Measuring degree of physical dependence to tobacco smoking with reference to individualization of treatment. Addict Behav. 1978;3(3-4):235-41.

23. Uysal MA, Kadakal F, Karșıdağ C, Bayram NG, Uysal Ö, Yılmaz V Fagerstrom test for nicotine dependence: reliability in a Turkish sample and factor analysis. Tuberk Toraks. 2004;52(2):115-21.

24. Önsüz MF, Topuzoğlu A, Algan A, Soydemir E, Aslan İ. Evaluation of the relationship between perception of tobacco packaging warning messages and the nicotine addiction levels of smokers. Marmara Medical Journal. 2009;22(2):111-22. (In Turkish.)

25. Cohen, J. Statistical power analysis for the behavioral sciences. 2nd ed Hillsdale, NJ: Lawrence Earlbaum Associates; 1988.

26. Erick PN, Smith DR. Prevalence of tobacco smoking among school teachers in Botswana. Tob Induc Dis. 2013 Nov 27;11(1):24.

27. Gündoğdu C, Oguzoncul AF. The relationship between smoking and exercise among physical education teachers in Turkey. Southeast Asian J Trop Med Public Health. 2013; 44(4):712-7.

28. Ohida T, Osaki Y, Mochizuki Y, Sekiyama M, Kawaguchi T, Ishii T, et al. Smoking behaviors and attitudes among school teachers in Mie, Japan. J Epidemiol. 2000;10(1):16-21.

29. The Ministry of Health of Turkey. Global adult tobacco survey: Turkey report - 2010. Ministry of Health Publication 803. Ankara: The Ministry of Health of Turkey; 2010

30. Binnal A, Rajesh G, Ahmed J, Denny C, Nayak SU. Insights into smoking and its cessation among current smokers in India. Asian Pac J Cancer Prev. 2013;14(5):2811-8.

Received December 9, 2014 Accepted in revised form December 10, 2015 